\title{
Increase in laminin expression in allergic airway remodelling and decrease by dexamethasone
}

\author{
P.E. Christie*, M. Jonas" ${ }^{\#}$ C-H. Tsai ${ }^{\top}$, E.Y. Chi" ${ }^{\#}$ W.R. Henderson Jr*
}

Increase in laminin expression in allergic airway remodelling and decrease by dexamethasone. P.E. Christie, M. Jonas, C-H. Tsai, E.Y. Chi, W.R. Henderson Jr. (C) ERS Journals Ltd 2004.

ABSTRACT: Lung expression of the extracellular matrix protein, laminin, and its receptor, laminin-1 receptor, were examined in a mouse model of asthma with airway remodelling.

Ovalbumin (OVA) was administered to BALB/c mice, intraperitoneally on days 0 and 14, and intranasally periodically between days 14 and 75 .

The mice developed airway esinophil and mononuclear inflammatory cell infiltration and fibrosis. On day 76, a marked increase in total laminin was seen in the airways of OVA-treated mice compared to controls by Western blot analysis. The increased laminin expression was detected immunocytochemically in the thickened subepithelial basement membrane and around airways and blood vessels. The OVA-treated mice showed increased expression of the $\alpha 1, \beta 1$, and $\gamma 1$ chains of the laminin- 1 isoform in monocytes, macrophages and eosinophils infiltrating the airways. Laminin-1 receptor expression was increased in inflammatory and endothelial cells in the lungs of OVAtreated mice compared to controls. Treatment of OVA-sensitised/challenged mice with dexamethasone reduced airway expression of laminin and laminin-1 receptor in OVAtreated mice but not airway hyperresponsiveness to methacholine.

Laminin deposition may be an important component of the airway remodelling observed in chronic allergic lung inflammation and is a process modulated by corticosteroids. Eur Respir J 2004; 24: 107-115.
Depts of $*$ Medicine and ${ }^{\#}$ Pathology, University of Washington, Seattle, WA, USA. "Dept of Pathology, Chung Shan Medical and Dental University, Taichung, Taiwan.

Correspondence: W.R. Henderson Jr, Dept of Medicine, Box 356523, University of Washington, 1959 NE Pacific Street, Seattle, WA 98195-6523, USA.

Fax: 12066859318

E-mail: joangb@u.washington.edu

Keywords: Allergy

eosinophils

extracellular matrix

fibrosis

inflammation

Received: February 52003

Accepted after revision: February 72004

This study was supported by National Institutes of Health (Bethesda, MD, USA) grants AI42989 and HL73722.
Airway remodelling consists of the structural changes that may occur in asthmatic airways in response to persistent inflammation. These changes include airway wall thickening with subepithelial fibrosis and hyperplasia of myofibroblasts, smooth muscle, the vasculature and goblet cells [1-3]. The intensity of the subepithelial fibrosis has been correlated with airway hyperresponsiveness to methacholine in patients with asthma [4]. Deposition of collagen and other extracellular matrix (ECM) proteins beneath the basement membrane in the lamina reticularis of the airways of asthmatics may lead to fibrosis and deterioration in respiratory function [5].

Laminins are ECM glycoproteins with distinct $\alpha, \beta$ and $\gamma$ chains that assemble to form heterotrimers in cells and tissues, in particular in basement membranes [6, 7]. Laminin isoforms exhibit different biological properties that may be important in lung morphogenesis and attachment of inflammatory cells [8]. Laminin-1 $(\alpha 1 \beta 1 \gamma 1)$ from the mouse Engelbreth-HolmSwarm (EHS) tumour cell prototype is the most extensively characterised isoform and is composed of $\alpha 1$ (400 kDa), $\beta 1$ $(200 \mathrm{kDa})$ and $\gamma 1(200 \mathrm{kDa})$ chains $[9,10]$. Laminin-1 binds to several cell surface receptors, including its high-affinity non-integrin 67-kDa monomeric receptor, designated laminin-1 receptor, other non-integrin receptors (e.g. dystroglycan, nidogen and heparin) and integrin receptors (e.g. $\alpha 6 \beta 1$, $\alpha 6 \beta 4$ and $\alpha 7 \beta 1$ ).

Laminin-1 is critical for basement membrane organisation during foetal lung development [11, 12]. Laminin is the primary noncollagenous component of basement membranes.

For editorial comments see page 1 .
Each of the laminin-1 $\alpha, \beta$ and $\gamma$ chains are expressed by epithelial and mesenchymal cells during lung development in mice and humans [13, 14]. Epithelial/mesenchymal interactions are key for $\alpha 1$ chain expression in the basement membrane at the epithelial/mesenchymal interface [11]. Lung epithelial cell proliferation is regulated by a specific domain in the cross region of the laminin $\alpha 1$ chain [13]. This region of the $\alpha 1$ chain is also important for attachment of epithelial and mesenchymal lung cells to each other and to basement membrane laminin [15]. Globular regions of the $\beta$ and $\gamma$ chains are important in inducing epithelial cell polarisation and airway lumen formation in embryonic lungs [15]. Interaction of laminin with heparan sulphate proteoglycans may also be important for lumen formation and maintenance of epithelial/mesenchymal structure in lung morphogenesis [16]. Another important effect of laminin-1 in lung development is maintenance of smooth muscle cell differentiation [11].

Laminin/integrin binding interactions are probably important for inflammatory cell accumulation in bronchial tissue. The laminin-binding integrin receptor $\alpha 6 \beta 1$ is expressed on human eosinophils and may facilitate eosinophil recruitment to sites of increased laminin expression in the lung [17, 18]. Monocytes, T-lymphocytes, neutrophils, epithelial cells, platelets and fibroblasts also express $\alpha 6 \beta 1$. Mouse peritoneal macrophages express cell-surface laminin, with increased laminin expression observed in thioglycollate-stimulated macrophages compared to resident cells [19].

Limited data exist regarding the role of laminin in airway remodelling in asthma. Immunocytochemically, increased 
thickness of the laminin $\alpha 1$ chain-positive airway subepithelial basement membrane layer is observed in patients with occupational asthma compared to normal controls [20]. Increased levels of laminin degradation products are recovered in bronchoalveolar lavage fluid from patients with severe asthma compared to those with mild asthma [21]. A mouse asthma model with the characteristic features of allergic airway inflammation and remodelling, including development of subepithelial fibrosis, has been developed [22]. In this chronic asthma model, the allergen-induced increase in the expression of laminin and its receptor, laminin-1 receptor, in the airways, and the modulation of these proteins and the allergic airway inflammatory/remodelling process by corticosteroid treatment, was examined. The source of the $\alpha 1, \beta 1$ and $\gamma 1$ laminin chains in the allergen-driven lung inflammatory sites was also examined.

\section{Materials and methods}

\section{Study animals}

All animal use procedures were approved by the University of Washington Animal Care Committee, University of Washington, Seattle, WA, USA, and performed according to the Helsinki convention for the use and care of animals.

Female BALB/c mice (aged 6-8 weeks; The Jackson Laboratory, Bar Harbor, ME, USA) received an intraperitoneal injection of $100 \mu \mathrm{g}$ ovalbumin (OVA) (Pierce, Rockford, IL, USA; $0.2 \mathrm{~mL} 500 \mu \mathrm{g} \cdot \mathrm{mL}^{-1}$ ) complexed with alum on days 0 and 14. This OVA-treated group $(n=10)$ received $50 \mu \mathrm{g}\left(50 \mu \mathrm{L} 1 \mathrm{mg} \cdot \mathrm{mL}^{-1}\right)$ OVA intranasally on days 14, 27, 28, 29, 47, 61, 73, 74 and 75. A corticosteroid treatment group $(\mathrm{n}=10)$ consisted of OVA-treated mice in which 200- $\mu$ L Alzet model 2004 miniosmotic pumps (Alza Corporation, Palo Alto, CA, USA) containing dexamethasone (Sigma Chemical Co., St Louis, MO, USA; $1.5 \mathrm{mg} \cdot \mathrm{kg}$ body weight ${ }^{-1}$ delivered at $6 \mu \mathrm{L} \cdot$ day) were placed on day 26 ( $24 \mathrm{~h}$ before intranasal OVA treatment) and replaced on day 54. In order to control for the effect of surgery and insertion of the miniosmotic pump, a group of mice $(n=9)$ receiving allergen and treated with saline-filled pump was included. The saline control group $(\mathrm{n}=10)$ received $0.2 \mathrm{~mL}$ normal saline with alum intraperitoneally on days 0 and 14 and $0.4 \mathrm{~mL}$ saline without alum intranasally on days $14,27,28,29,47,61$, 73,74 and 75 .

\section{Pulmonary mechanics}

On day 76, $24 \mathrm{~h}$ after the final intranasal administration of either normal saline or OVA, noninvasive pulmonary mechanics were determined after aerosolisation of methacholine in conscious freely moving spontaneously breathing mice using whole-body plethysmography (Model PLY 3211; Buxco Electronics, Inc., Sharon, CT, USA) [22, 23]. Mice were challenged with aerosolised saline and increasing doses of methacholine $\left(5\right.$ and $20 \mathrm{mg} \cdot \mathrm{mL}^{-1}$ ) generated by an ultrasonic nebuliser (DeVilbiss Health Care, Inc., Somerset, PA, USA) for $2 \mathrm{~min}$. The degree of bronchoconstriction was expressed as enhanced pause (Penh), a calculated dimensionless value, which correlates with measurement of airway resistance, impedance and intrapleural pressure; Penh readings were taken and averaged over 4 min after each nebulisation challenge. Penh was calculated as follows: $\mathrm{Penh}=(t \mathrm{E} / \mathrm{tR}-1)$ $\mathrm{PEF} / \mathrm{PIF}$, where $t \mathrm{E}$ is expiration time, $t \mathrm{R}$ relaxation time, $\mathrm{PEF}$ peak expiratory flow and PIF peak inspiratory flow. The time taken for the box pressure to change from maximum to a user-defined percentage of the maximum represents $t \mathrm{R}$. $t \mathrm{R}$ measurement was begun at the maximum box pressure and ended at $40 \%$. Penh results are reported as a percentage of the value obtained for the air control. Each mouse was then exsanguinated by cardiac puncture, and the left lung was tied off at the main-stem bronchus and left lung (upper and lower lobes) tissues obtained. The lung tissue was divided into separate samples for either Western blot analysis or immunocytochemistry.

\section{Western blot analysis}

Lung tissue was homogenised using TRI REAGENT (Molecular Research Center, Inc., Cincinnati, OH, USA), and the homogenate separated into aqueous and organic phases by addition of chloroform and centrifugation. Proteins were sequentially precipitated from the organic phase using isopropanol. The protein was precipitated by centrifugation, and the pellet washed three times in $0.3 \mathrm{M}$ guanidine hydrochloride in 95\% ethanol. Protein solubilisation was partially achieved by dissolving proteins in a solution containing $1 \%$ sodium dodecylsulphate for $10 \mathrm{~min}$ at $50^{\circ} \mathrm{C}$. After centrifugation, a further solubilisation step was performed by dissolving the pellet in $200 \mu \mathrm{L} 10 \mathrm{M}$ urea in $0.05 \mathrm{M}$ tris(hydroxymethyl)aminomethane (Tris)/ $\mathrm{HCl}$ (pH 7.6). After centrifugation for $10 \mathrm{~min}$ at $10,000 \times \mathrm{g}$ at $4^{\circ} \mathrm{C}$, the supernatant was stored at $-20^{\circ} \mathrm{C}$ for Western blot analysis. Mouse lung tissue was assayed for total protein using a commercial protein assay (Bio-Rad Laboratories, Hercules, CA, USA).

Protein electophoresis and Western blot analysis were performed using the Novex $(\mathbb{R})$ Xcell SureLock ${ }^{\mathrm{TM}}$ Mini-Cell system (Invitrogen, Inc., Carlsbad, CA, USA) and NuPAGE gels and buffers (Invitrogen, Inc.). Samples containing $0.04 \mathrm{mg} \cdot \mathrm{mL}^{-1}$ total protein were loaded in all lanes of a 3-8\% Tris/acetate gel. Prestained protein standards (molecular weight range $41-210 \mathrm{kDa}$ ) were purchased from Invitrogen, Inc. In order to assess protein separation, gels were stained using Coomassie R-250 (Invitrogen, Inc.). Proteins separated by electrophoresis were transferred to $0.2-\mu \mathrm{m}$ polyvinylidene difluoride membranes for Western blot analysis. Membranes were rinsed in $0.01 \mathrm{M}$ phosphate-buffered saline (PBS $(0.9 \% \mathrm{NaCl}) ; \mathrm{pH} 7.4)$ containing $0.05 \%$ Tween 20 (TPBS) (Sigma Chemical Co), blocked with 5\% dry nonfat milk for either $1 \mathrm{~h}$ at room temperature $\left(24^{\circ} \mathrm{C}\right)$ or overnight at $4{ }^{\circ} \mathrm{C}$ and then incubated with $5 \mathrm{~mL}$ antilaminin primary antibody (Sigma Chemical Co; 1:1,000 dilution) diluted in 5\% dry nonfat milk for $1-2 \mathrm{~h}$ at room temperature. After rinsing in TPBS, membranes were incubated with $5 \mathrm{~mL}$ secondary antibody (i.e. anti-immunoglobulin (Ig) G coupled to horseradish peroxidase (DAKO, Carpinteria, CA, USA; 1:1,000 dilution) in 5\% nonfat milk). After rinses in TPBS, PBS and distilled water, the bands corresponding to immunoreactive proteins were visualised by treatment with substrate (NovaR$\mathrm{ED}^{\mathrm{TM}}$; Vector Laboratories, Inc., Burlingame, CA, USA). Gel bands were compared to those obtained using $10 \mu \mathrm{g}$ purified laminin from mouse EHS sarcoma basement membrane (Sigma Chemical Co) [24].

\section{Light microscopy: immunocytochemistry and morphometry}

For immunocytochemistry using light microscopy [25], mouse lung tissue was fixed in methyl Carnoy's solution and embedded in paraffin. Sections $(5 \mu \mathrm{m})$ were cut and placed on SuperFrost Plus slides (VWR Scientific, West Chester, PA, USA). The sections were deparaffinised, hydrated with 
distilled water and then washed in PBS ( $\mathrm{pH}$ 7.4) for $10 \mathrm{~min}$. All immunolabelling procedures were carried out at room temperature $\left(24^{\circ} \mathrm{C}\right)$. Endogenous peroxidase was inactivated by incubating the tissue sections in $6 \%$ hydrogen peroxide for $6 \mathrm{~min}$. In order to prevent nonimmunological attachment of antibodies, the tissue sections were blocked with 5\% dry nonfat milk in PBS for $45 \mathrm{~min}$. The primary antibody was diluted in 5\% dry nonfat milk in PBS to a previously determined optimal concentration, applied to the tissue sections and the sections incubated for $1-2 \mathrm{~h}$. The primary antibodies consisted of polyclonal antilaminin (Sigma Chemical Co.; $2 \mu \mathrm{g} \cdot \mathrm{mL}^{-1}$ ), polyclonal antilaminin $\alpha 1, \beta 1$ and $\gamma 1$ chain (Santa Cruz Biotechnology, Inc., Santa Cruz, CA, USA; each $4 \mu \mathrm{g} \cdot \mathrm{mL}^{-1}$ ), and monoclonal antilaminin-1 receptor (Clone MLuC5; NeoMarkers, Inc., Fremont, CA, USA; $\left.4 \mu \mathrm{g} \cdot \mathrm{mL}^{-1}\right)$. Control slides were treated only with $5 \%$ dry nonfat milk. After incubation, the sections were washed in TPBS. The secondary anti-IgG antibody, which was conjugated to horseradish peroxidase, was diluted in 5\% dry nonfat milk in PBS, applied to the sections and the sections incubated for $1.5 \mathrm{~h}$. After incubation, the sections were thoroughly washed in TPBS. The peroxidase substrate solution, NovaRED, was prepared as instructed by the manufacturer directly before use. The substrate solution was applied to the sections and, depending on the type of antibody used, incubated for 5-20 min. The samples were rinsed in distilled water and the nuclei counterstained with $1 \%$ methyl green in $0.1 \mathrm{M}$ sodium acetate $(\mathrm{pH} 4)$ for $30-60 \mathrm{~s}$. The sections were differentiated in $90 \%$ ethanol, dehydrated in absolute ethanol, cleared in xylene and mounted on glass slides with Permount (Fisher Scientific, Pittsburgh, PA, USA).

Morphometric analysis of lung tissue for laminin and laminin-1 receptor expression, as visualised by light microscopy, was performed by individuals blinded to the protocol design. The degree of laminin expression using immunocytochemistry was assessed on a semiquantitative scale of $0-4$ and the number of laminin-1 receptor-positive cells per unit airway area $\left(2,200 \mu \mathrm{m}^{2}\right)$ determined morphometrically [22, 25-29]. Ten randomly selected sections throughout the left lung tissue blocks per animal were submitted to morphometric analysis. At a magnification of $\times 400$, using a Whipple micrometer disc (Bausch \& Lomb, Rochester, NY, USA), each field represented a tissue area of $2,200 \mu \mathrm{m}^{2}$. The total number of nucleated cells (including all monocytes, macrophages, eosinophils, neutrophils, mast cells, epithelial cells, endothelial cells and fibroblasts) in the lung parenchyma in each field was counted using a point counting system (ImagePro $\mathbb{R}$ Plus point counting system software, Version 1.2 for Windows $^{\mathrm{TM}}$; Media Cybernetics, Silver Spring, MD, USA). The error of repeat counting was $<5 \%$ by this method [30].

\section{Immunogold electron microscopy}

Immunogold electron microscopy was performed as previously described [31]. The lung sections were incubated in the presence or absence of antilaminin (Sigma Chemical Co; $10 \mu \mathrm{g} \cdot \mathrm{mL}^{-1}$ ) at a dilution of 1:50 in PBS for $2 \mathrm{~h}$ at $4^{\circ} \mathrm{C}$, rinsed in PBS and treated with $12-\mathrm{nm}$ colloidal gold-AffiniPure ${ }^{\mathrm{TM}}$ anti-IgG (Jackson ImmunoResearch Laboratories, Inc., West Grove, PA, USA) at a dilution of $1: 5$ in PBS for $12 \mathrm{~h}$ at $4{ }^{\circ} \mathrm{C}$ and examined using a Model 1200EX electron microscope (JEOL Ltd, Tokyo, Japan).

\section{Statistical analysis}

Data are reported as mean \pm SEM. Differences were analysed for significance $(\mathrm{p}<0.05)$ using the Mann-Whitney U-test, a nonparametric nonpaired analysis with correction for multiple comparisons, or analysis of variance using the least significant difference method as indicated.

\section{Results}

\section{Airway laminin and laminin-1 receptor expression: effect} of dexamethasone

On day 76, $24 \mathrm{~h}$ after the final intranasal OVA or saline treatment, lung tissue was obtained in order to assess expression of laminin, laminin-1 chains $(\alpha 1, \beta 1$ and $\gamma 1)$ and laminin-1 receptor in the airways. The effect of dexamethasone on airway laminin and laminin-1 receptor expression was determined.

\section{Lung laminin}

Total laminin levels in lung tissue from OVA-treated and control mice were determined by Western blot analysis. A marked increase in laminin levels (both 200- and 400-kDa chains) was observed in the lung tissue of OVA-treated mice compared to saline controls (fig. 1).

Using light microscopy, an extensive eosinophil and mononuclear cell infiltrate was seen around the airways and pulmonary blood vessels in the lung interstitium of OVAsensitised/challenged mice compared to saline-treated control mice (fig. $2 \mathrm{a}$ and b). In the OVA-treated mice, laminin was detected immunocytochemically in the lungs, around the airways and blood vessels (fig. 3a); little laminin expression was observed in saline-treated controls (fig. 3c). On morphometric analysis (fig. 4), laminin expression ( $0-4$ scale) increased to $2.2 \pm 0.2(\mathrm{n}=10)$ in OVA-treated mice compared to $0.4 \pm 0.1 \quad(n=10)$ in controls $(\mathrm{p}<0.0001)$. Dexamethasone

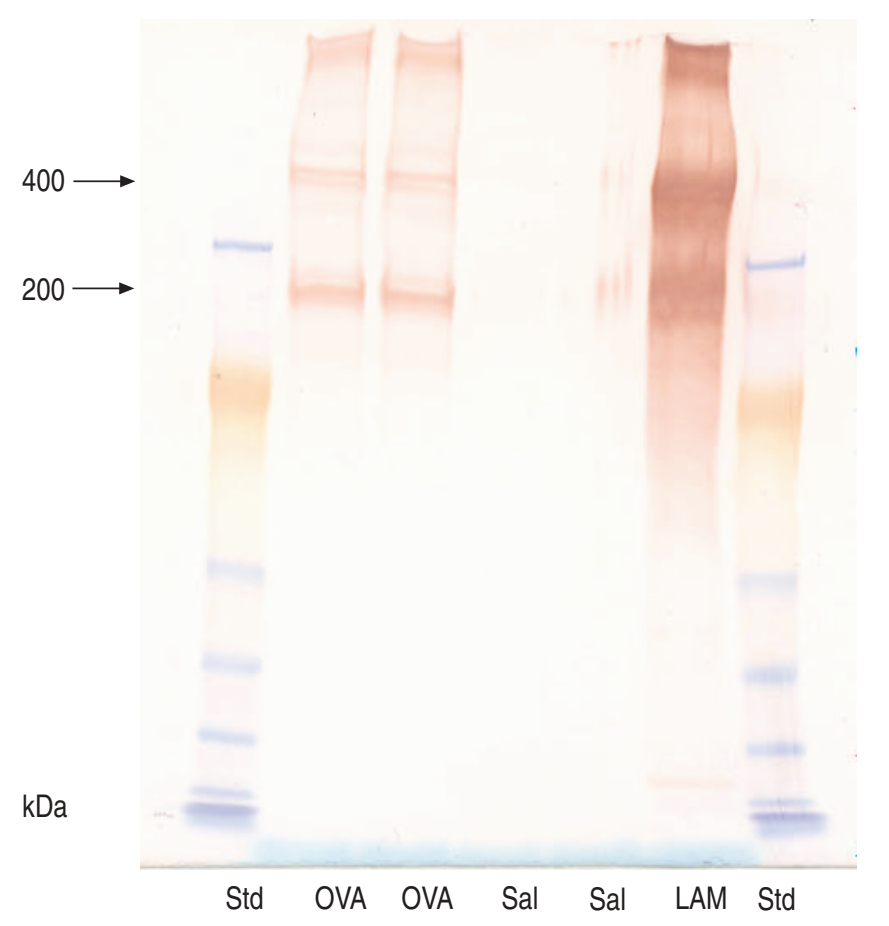

Fig. 1. - Laminin expression in the lungs of ovalbumin (OVA)-treated mice and saline (sal)-treated controls determined by Western blot analysis. Mouse laminin (LAM) from Engelbreth-Holm-Swarm tumour cells consists of disulphide-linked chains of 200 and $400 \mathrm{kDa}$ [24]. Std: protein molecular mass standards $(41-210 \mathrm{kDa})$. 

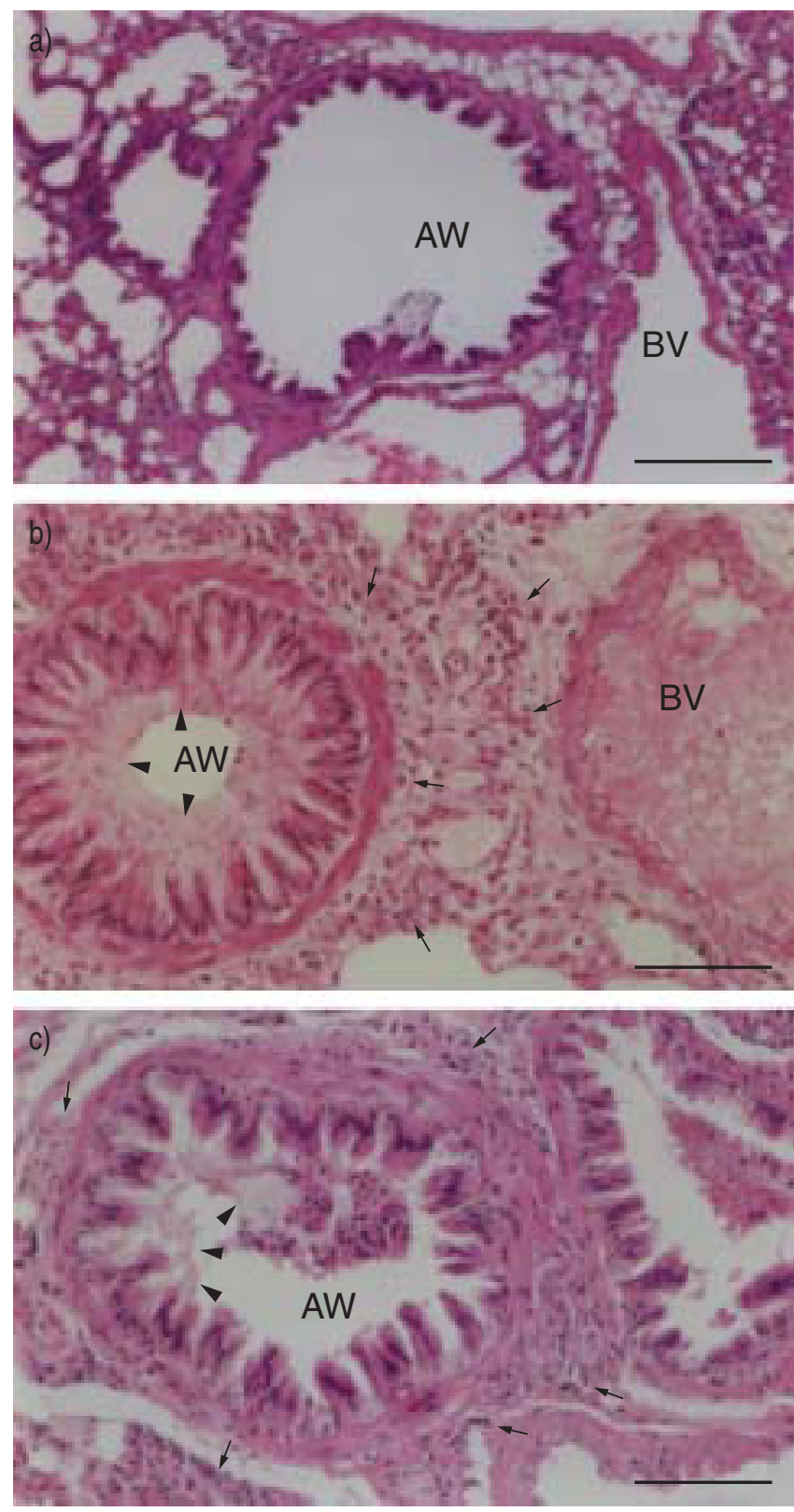

Fig. 2. - Allergen-induced airway inflammation in ovalbumin (OVA)treated mice, and lack of effect of surgery and miniosmotic pump insertion. Lung tissue was obtained on day 76 from a) saline-treated control mice and b, c) OVA-sensitised/challenged mice in the b) absence and c) presence of a $200-\mu \mathrm{L}$ saline-filled miniosmotic pump, inserted on day 26 and replaced on day 54. a) Inflammatory cells are absent around the airways (AW) and blood vessels (BV); and little mucus is visible in the airways. b) A dense inflammatory cell infiltrate (arrows) can be seen around the airways and blood vessels; eosinophils and mononuclear inflammatory cells (monocytes and macrophages) are the predominant cells in this infiltrate. Mucus occlusion (arrowheads) of the airway lumen is visible. c) Airway mucus release (arrowheads) and inflammatory cell influx (arrows) are not reduced. Haematoxylin and eosin stain; internal scale bars $=100 \mu \mathrm{m}$.

treatment reduced airway laminin expression to $0.7 \pm 0.1$ $(\mathrm{n}=10)$ in OVA-sensitised/challenged mice $(\mathrm{p}<0.0001$ versus OVA alone) (figs $3 \mathrm{~b}$ and 4). The lungs of control mice, receiving OVA and treated with saline-filled miniosmotic pumps, were indistinguishable from those of mice treated with OVA alone (fig. $2 b$ and c), indicating a lack of effect of the surgery and minipumps on the allergen-induced inflammatory/remodelling response.

As determined by electron microscopy, the subepithelial basement membrane of the lungs of OVA-sensitised/challenged mice was thickened in comparison to that of saline-treated controls (fig. 5a and b). Immunogold electron microscopy localised laminin deposition to the thickened subepithelial airway and alveolar basement membrane in OVA-treated mice (fig. 5c).

\section{Airway laminin $\alpha 1, \beta 1$ and $\gamma 1$ chains}

Laminin $\alpha 1, \beta 1$ and $\gamma 1$ chains were detected immunocytochemically in monocytes, macrophages and eosinophils infiltrating the airways of OVA-treated mice (fig. 6). They were not observed in the lungs of either saline controls or OVA-treated mice administered dexamethasone (not shown).

\section{Airway laminin-1 receptor}

As assessed immunocytochemically, laminin-1 receptor expression increased markedly in the airways of OVA-treated compared to saline-treated mice (fig. $7 \mathrm{a}$ and c). Laminin-1 receptor expression occurred primarily in inflammatory cells (i.e. monocytes, macrophages and eosinophils) infiltrating the airways and blood vessel endothelial cells in the OVA-treated mice (fig. 7a). On morphometric analysis, laminin-1 receptor levels increased to $7.3 \pm 0.7$ laminin-1 receptor-positive cells.unit area lung tissue ${ }^{-1} \quad(n=10)$ in OVA-treated mice compared to $0.4 \pm 0.2$ laminin-1 receptor-positive cells-unit area lung tissue ${ }^{-1}$ in controls $(\mathrm{n}=10) \quad(\mathrm{p}<0.0001) \quad($ fig. 8). Dexamethasone administration reduced laminin-1 receptor expression in the airways of OVA-treated mice to $3.1 \pm 0.4$ laminin-1 receptor-positive cells $\cdot$ unit area lung tissue ${ }^{-1}(n=10$; $\mathrm{p}<0.0001$ versus OVA alone) (figs $7 \mathrm{a}$ and $\mathrm{b}$, and 8).

\section{Allergen-induced airway hyperresponsiveness to methacholine: effect of dexamethasone}

Airway reactivity was evaluated on day $76,24 \mathrm{~h}$ after the final intranasal challenge with OVA, by noninvasive in vivo plethysmography. In the OVA group, airway hyperreactivity was seen after aerosolised methacholine challenge ( 5 and $\left.20 \mathrm{mg} \cdot \mathrm{mL}^{-1}\right)$, with a significant increase in Penh compared to the saline group $\left(\mathrm{p}<0.05\right.$ at both 5 and $20 \mathrm{mg} \cdot \mathrm{mL}^{-1}$ methacholine) (fig. 9). Dexamethasone did not significantly reduce the airway hyperresponsiveness to aerosolised methacholine in OVA-treated mice compared to the saline controls $(\mathrm{p}<0.05$ at both 5 and $20 \mathrm{mg} \cdot \mathrm{mL}^{-1}$ methacholine) (fig. 9).

\section{Discussion}

Increased expression of total laminin, laminin-1 chains $(\alpha 1$, $\beta 1$ and $\gamma 1$ ) and laminin-1 receptor was observed in the airways of OVA-sensitised mice, challenged with allergen over a 2-month period, compared to saline-treated control mice. The mouse chronic asthma model employed in the present study exhibits key pathological features of airway remodelling observed in patients with persistent asthma. The airway inflammatory response in this asthma model is characterised by extensive airway eosinophil and mononuclear inflammatory cell infiltration, goblet cell hyperplasia with extensive airway occlusion by mucus, and airway fibrosis with deposition of collagen and other ECM proteins [22]. 

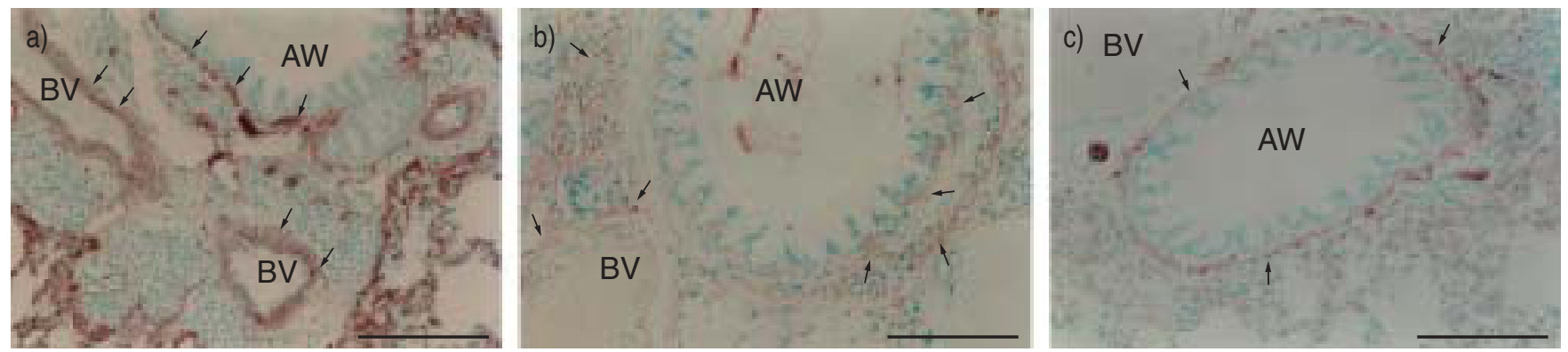

Fig. 3. - Immunocytochemical determination of effect of dexamethasone on airway laminin expression in ovalbumin (OVA)-treated mice. Airway tissue was obtained from OVA-treated mice in the a) absence and b) presence of dexamethasone $\left(1.5 \mathrm{mg} \cdot \mathrm{kg}\right.$ body weight $\left.{ }^{-1}\right)$, and c) from saline controls. a) Laminin expression (arrows) is intense around the airways (AW) and blood vessels (BV) in OVA-treated mice. c) Relatively little laminin expression (arrows) is seen around the airways and blood vessels of saline-treated controls. Internal scale bars $=100 \mu \mathrm{m}$.

A primary feature of the airway remodelling process in patients with asthma is deposition of ECM proteins leading to airway wall thickening. The increased airway laminin expression observed in the present mouse chronic asthma model may be important in the development of fibrosis. Increased lung expression of type-2 T-helper cell cytokines, including interleukin (IL)-13 [22], was observed in the OVA-treated mice. Prior work by LEE et al. [32] demonstrated that IL-13 induces lung fibrosis in mice by selective activation of transforming growth factor- $\beta$ (TGF- $\beta$ ). TGF- $\beta$ induces expression of laminin $\alpha 1$ chains in rat mesangial cells [33] and laminin $\gamma 1$ chains in mouse distal respiratory epithelial cells [34]. The ability of laminin, via a laminin/nidogen binding site, to form a lattice-type assembly with collagen in the lung matrix may lead to airway wall thickening. Alveolar wall thickening observed in this chronic asthma model may adversely affect gas exchange in the lungs.

The high-affinity 67-kDa laminin receptor (i.e. laminin-1 receptor) has gained importance as a marker in metastatic disease, with increasing evidence for a role in chronic inflammatory processes through its upregulation by cytokines. Laminin and fibronectin increase laminin-1 receptor expression, suggesting a feedback mechanism that enhances laminin-1 receptor/laminin binding. Adhesive interaction between laminin and mast cells may also be important in

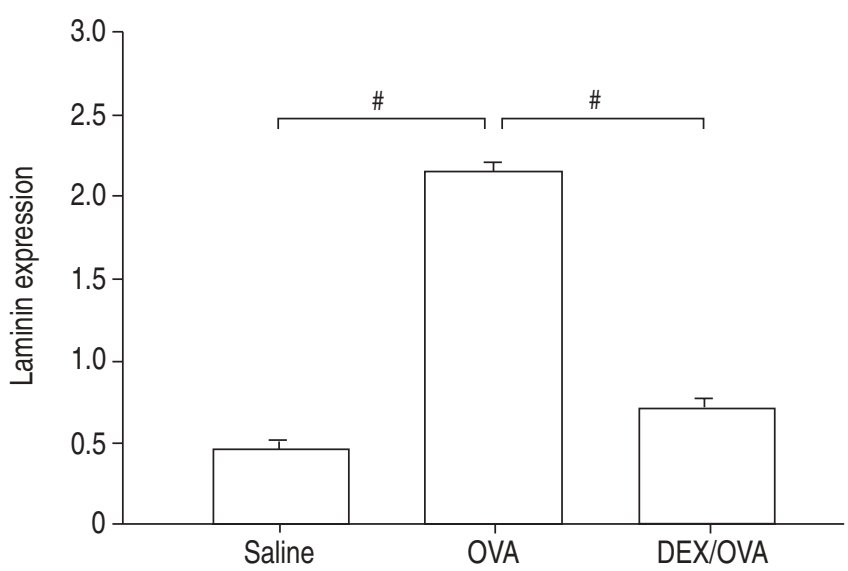

Fig. 4.-Morphometric analysis of effect of dexamethasone on airway laminin expression in ovalbumin (OVA)-treated mice. Lung tissue was obtained from saline-treated mice $(\mathrm{n}=10)$ and OVA-sensitised/challenged mice, in the absence $(\mathrm{n}=10)$ or presence of $1.5 \mathrm{mg} \cdot \mathrm{kg}$ body weight $^{-1}$ dexamethasone (DEX; $\left.n=10\right)$. The intensity of laminin expression in the lung tissue was determined on a $0-4$ scale. Data are presented as mean \pm SEM. ${ }^{\#}: \mathrm{p}<0.0001$.
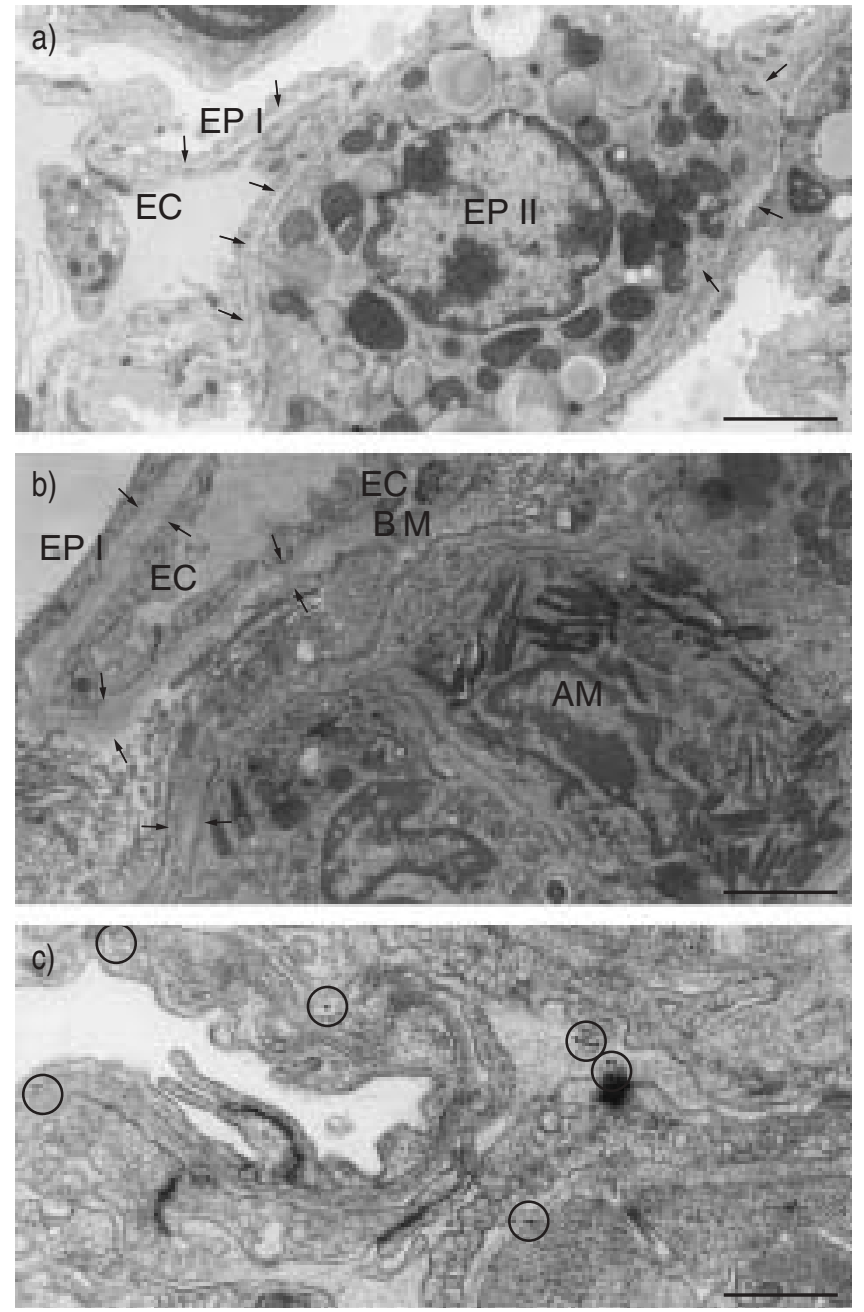

Fig. 5.-Immunogold localisation of laminin in alveolar epithelial basement membrane from ovalbumin (OVA)-treated mice. Airway tissue was obtained from a) saline-treated and b, c) OVA-sensitised/ challenged mice b) without and c) with immunogold labelling of laminin and examined electron microscopically. a) The thin $(<1 \mu \mathrm{m}$ thickness) basement membrane (arrows) is seen between endothelial cells (EC) and type-I epithelial cells (EP I), with type-II epithelial cells (EP II) in close proximity. b) The basement membrane (BM; arrows) between EP I and EC is thickened compared to controls. An alveolar macrophage (AM) with ingested Charcot-Leyden-like crystal [22] can be seen. c) Laminin-specific 12-nm immunogold particles appear as black dots (circled). These particles localise to the basement membrane in the airways of the OVA-treated mice. Internal scale bars $=a, b) 2 \mu \mathrm{m}$, c) $1 \mu \mathrm{m}$. 

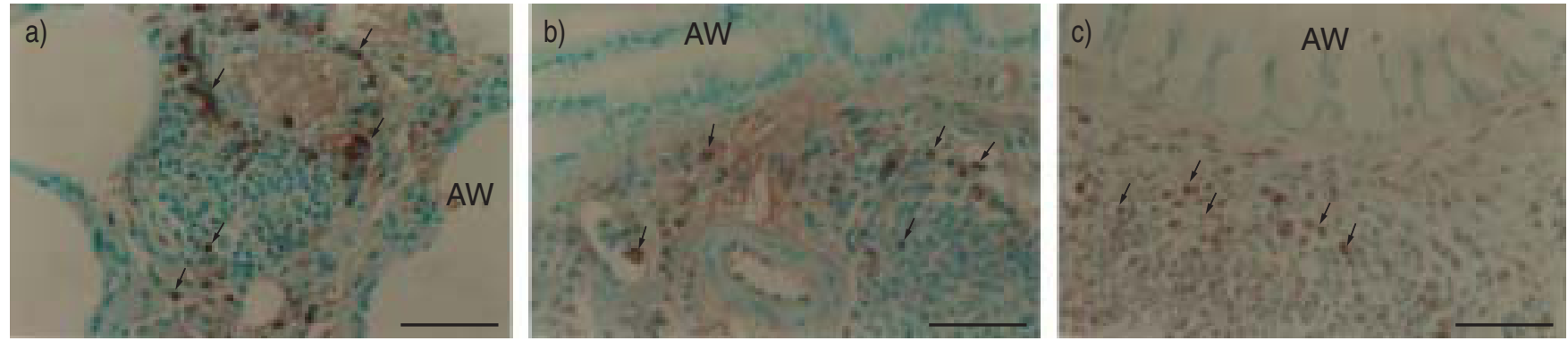

Fig. 6. - Localisation of laminin $\alpha 1, \beta 1$ and $\gamma 1$ chains in alveolar walls from ovalbumin (OVA)-treated mice. Lung tissue was obtained from OVA-treated mice and examined immunocytochemically for laminin a) $\alpha 1$, b) $\beta 1$ and c) $\gamma 1$ chains. a) Laminin $\alpha 1$ chain immunoreactivity is seen in monocytes, macrophages and eosinophils (arrows) infiltrating the airways (AW). b, c) Laminin $\beta 1$ and $\gamma 1$ chains also localise to inflammatory cells (arrows) infiltrating the airways in the OVA-sensitised/challenged mice. Internal scale bars $=50 \mu \mathrm{m}$.
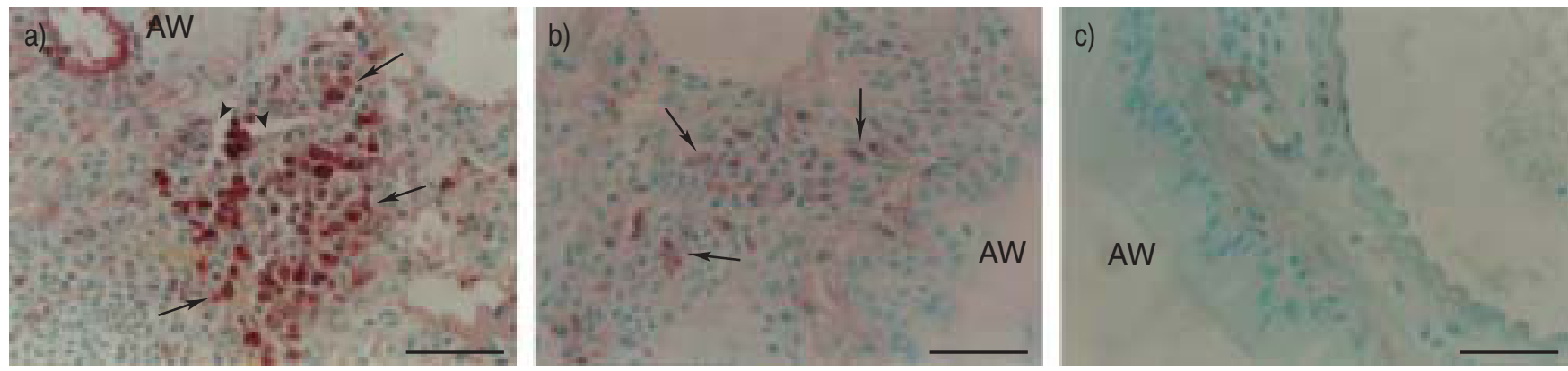

Fig. 7. - Immunocytochemical determination of effect of dexamethasone on airway laminin-1 receptor expression in ovalbumin (OVA)-treated mice. Lung tissue was obtained from OVA-sensitised/challenged mice in the a) absence and b) presence of dexamethasone (1.5 mg.kg body weight ${ }^{-1}$ ), and c) from saline-treated mice and examined for laminin-1 receptor expression. a) Laminin-1 receptor expression is seen in inflammatory cells (arrows) and blood vessel endothelial cells (arrowheads) in the airways (AW) of OVA-treated mice. b) Comparatively decreased laminin-1 receptor expression is observed in inflammatory cells (arrows) infiltrating the airways of OVA-treated mice given dexamethasone. c) Little laminin-1 receptor expression is seen in the airways of controls. Internal scale bars $=50 \mu \mathrm{m}$.

allergic inflammation via expression of $\alpha_{6}$ integrin on mast cells [35]. Mouse mast cell lines and primary bone marrow cultured mast cells attach to both laminin-1 and laminin-2 isoforms, and this attachment is blocked by antibody directed against $\alpha_{6}$ integrins [35]. The results of these interactions may promote enhanced release of mast cell granule constituents.

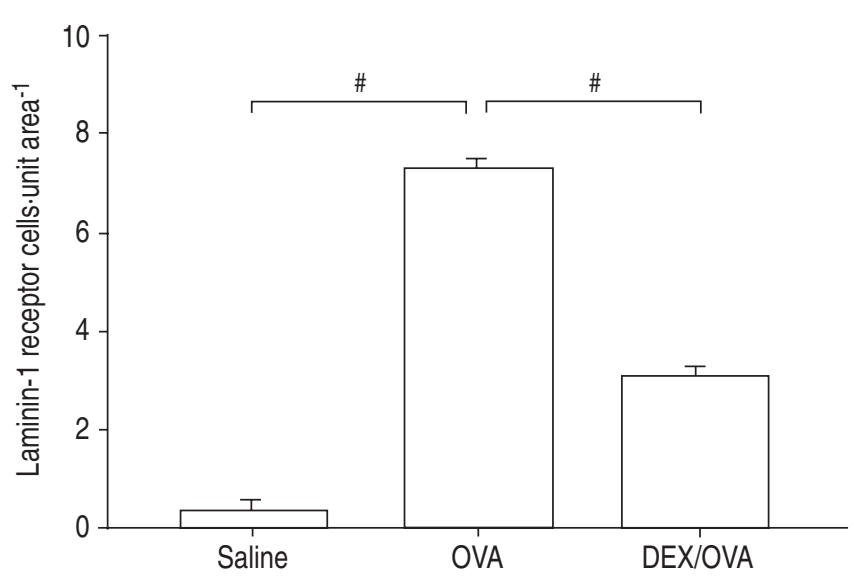

Fig. 8. - Morphometric analysis of effect of dexamethasone on airway laminin-1 receptor expression in ovalbumin (OVA)-treated mice. Lung tissue was obtained from saline-treated mice $(n=10)$ and OVAsensitised/challenged mice, in the absence $(n=10)$ or presence of $1.5 \mathrm{mg} \cdot \mathrm{kg}$ body weight ${ }^{-1}$ dexamethasone (DEX; $\mathrm{n}=10$ ). The number of laminin-1 receptor-positive cells per unit area $\left(2,200 \mu \mathrm{m}^{2}\right)$ of lung tissue was determined morphometrically. Data are presented as mean \pm SEM. ${ }^{\#}: \mathrm{p}<0.0001$.
The cellular pathways responsible for increased laminin deposition in the airways are unknown. Increased laminin deposition and secretion into the airways might reflect lung injury and fibrotic repair similar to that observed in the airways of preterm infants [36]. The increased deposition of laminin in a murine model of chronic asthma supports a role

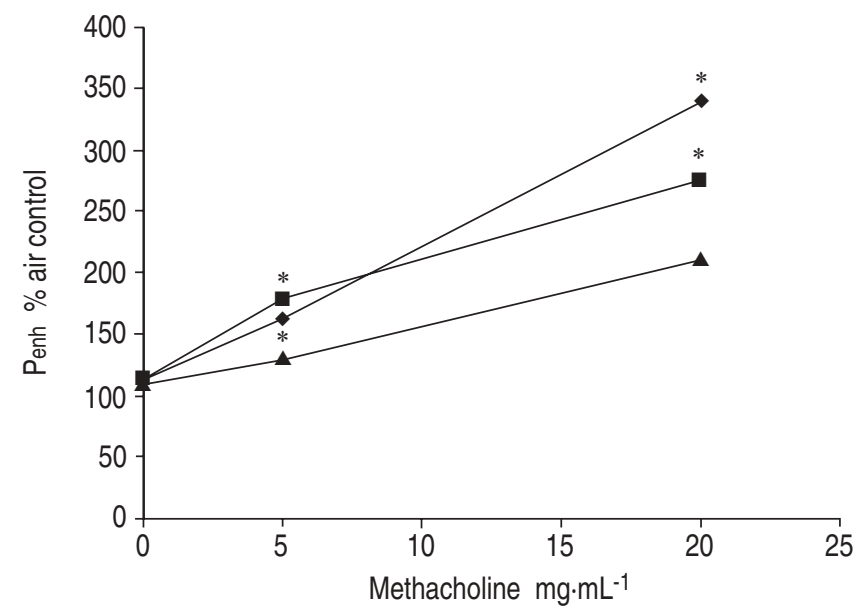

Fig. 9.-Effect of dexamethasone on pulmonary mechanics in response to aerosolised methacholine. The degree of bronchoconstriction (expressed as enhanced pause (Penh)) was determined on day 76 in saline-treated control animals $(\boldsymbol{\Lambda})$ and ovalbumin-sensitised/challenged mice in the absence ( $\mathbf{0}$ ) or presence $(0)$ of $1.5 \mathrm{mg} \cdot \mathrm{kg}$ body weight $^{-1}$ dexamethasone treatment. *: $\mathrm{p}<0.05$ versus saline (analysis of variance). 
for laminin in persistent asthma. This may be due to the ability of laminin and collagen to form a lattice-type assembly in the basement membrane, leading to thickening of asthmatic airway walls. Laminin/integrin binding interactions may also have important effects on inflammatory cell trafficking to the lung. The $\alpha_{6} \beta_{1}$ integrin present on eosinophils and other inflammatory cells functions as a laminin receptor, which may contribute to the localisation of these cells at inflammatory sites. The observation that expression of $\alpha_{6} \beta_{1}$ integrin and the laminin receptor on normal murine lung fibroblasts is increased by the inflammatory cytokines interferon gamma and tumour necrosis factor- $\alpha$ could result in retention of lung fibroblasts in regions undergoing repair of injury. There is an important relationship between proteinases which degrade extracellular matrix proteins and laminins. Laminin upregulates urokinase and matrix metalloproteinase 9 expression by macrophages. Incubation of RAW264.7 macrophages with a laminin peptide derived from the $\alpha 1$ chain but not intact laminin-1 triggers protein kinase $\mathrm{C}$-dependent activation of the extracellular signal-regulated kinase- 1 and -2 mitogenactivated protein kinase pathway, leading to upregulation of urokinase-type plasminogen activator and matrix metalloproteinase 9 expression [37, 38].

In the present mouse chronic asthma model, laminin $\alpha 1, \beta 1$ and $\gamma 1$ chains were detected in inflammatory cells (i.e. monocytes, macrophages and eosinophils) in the airways of OVA-sensitised/challenged mice. Since the laminin chains were not seen in the saline controls or the steroid-treated OVA group, it is likely that the infiltrating inflammatory cells are the source of the laminin chains in the OVA-sensitised/ challenged mice. The laminin $\alpha 1$ chain may be important in controlling basement membrane formation. Prior studies, using a transfectable human cell line to determine the fate of individual laminin chains in the absence of their normal partners, found that the $\alpha 1$ chain is expressed and secreted as a single chain, whereas, the $\beta 1$ and $\gamma 1$ chains require $\alpha 1$ chain coexpression for their extracellular secretion and assembly into $\alpha \beta \gamma$ heterotrimers [39]. Thus laminin-1 secretion may be controlled by $\alpha$ chain gene production, and, once laminin-1 assembly occurs, it may be incorporated into the basement membrane. It is possible that other laminin isoforms contribute to the airway remodelling process in asthma. Immunohistochemical staining has revealed increased deposition of laminin $\alpha 2$ chains along the epithelial margin of the basement membrane in severe chronic asthma, which may be the result of increased tissue turnover in the asthmatic airways [20]. Since the molecular pathways resulting in laminin chain synthesis and the mechanisms of assembly of these isoforms are unknown, it is possible that different laminin isoforms are present in different asthma phenotypes.

In the present study, dexamethasone inhibited allergeninduced expression of total laminin, laminin-1 chains and laminin-1 receptor in the lungs of OVA-treated mice. The effects of corticosteroids on airway remodelling and subepithelial fibrosis have been examined in other animal asthma models and patients with asthma with varying results. In a mouse asthma model with three allergen challenges beginning 40 days after initial sensitisation, subepithelial fibrosis was reduced by daily treatment with dexamethasone for 8 days during the allergen-challenge period [40]. In this model, treatment with dexamethasone for 15 days after allergen challenge partially resolved previously established subepithelial fibrosis [40]. In another mouse asthma model, mice exposed to either single or five daily OVA challenges showed a time-dependent increase in airway epithelial cell proliferation [41]. Dexamethasone pretreatment blocked the inflammatory response in this model, but only partially inhibited the remodelling process in the lungs [41]. In sensitised Brown Norway rats exposed to aerosolised OVA for 2 weeks, concomitant treatment with aerosolised fluticasone propionate decreased OVA-induced airway structural changes (i.e. in airway wall area, epithelial cell and goblet cell proliferation, and fibronectin deposition) [42]. However, fluticasone administered after allergen exposure failed to reverse established airway structural changes in these rats. In this rat model, when OVA exposure is increased by an additional 2 weeks, enhanced airway collagen deposition is observed [43]. Treatment with fluticasone during this last 2 weeks of allergen challenge inhibits the additional increase in collagen deposition [43]. It is of interest that combining salmeterol with fluticasone during the last 2 weeks of this rat asthma model results in increased airway wall thickness and deposition of collagen and fibronection in the lungs [44].

Although many studies in patients with asthma demonstrate a reduction in the number of airway inflammatory cells after corticosteroid treatment, there are few studies on the effect of corticosteroids on airway ECM protein expression and remodelling. Serum from an asthmatic individual has previously been shown to increase production of laminin $\gamma 1$ chains and other ECM components (i.e. fibronectin, perlecan and chondroitin sulphate) by human airway smooth muscle cells in vitro [45]. However, beclomethasone treatment failed to reduce this stimulatory effect of the asthmatic serum [45]. In one study of 10 patients with severe asthma, despite longterm corticosteroid treatment (mean $3.7 \mathrm{yrs}$ ), the asthmatic subjects showed thickening of basement membrane reticular collagen comparable to controls without asthma [46]. In contrast, in 24 patients with asthma, 6 months of treatment with inhaled beclomethasone dipropionate, compared to placebo, decreased the number of activated eosinophils, T-cells and fibroblasts and the thickness of the lamina reticularis in biopsy samples from the bronchial mucosa [47]. In another bronchial bioptic study of 14 patients with asthma, 3 months of budesonide treatment (compared to baseline) reduced the number of infiltrating eosinophils and lymphocytes and improved the structure of the bronchial epithelium [48]. Increased expression of the ECM protein tenascin has been observed in the bronchial subepithelial reticular basement membrane layer of patients with seasonal birch pollen asthma [49] and competitive cross-country skiers [50]. Budesonide treatment reduced this increased expression of airway tenascin in the patients with seasonal asthma [49] but not in the elite skiers [51, 52].

Chronic allergen challenge in mice leads to the development of increased subepithelial ECM accumulation and fibrosis, as assessed morphometrically [22, 53, 54], and airway dysfunction characterised by airway hyperresponsiveness to methacholine [22, 54]. Despite significant reduction by dexamethasone of the increased airway laminin and laminin-1 expression in the OVA-treated mice, corticosteroid treatment had no significant effect on airway hyperreactivity to aerosolised methacholine, as determined by noninvasive plethysmography. This dissociation of the airway remodelling from the airway hyperreactivity changes is consistent with prior data from this same mouse model of chronic allergeninduced airway remodelling, in which the cysteinyl leukotriene 1 receptor antagonist montelukast failed to reduce airway hyperreactivity despite blocking the increased airway collagen deposition. Similarly, in prior work using an acute asthma model, it was found that intraperitoneal monoclonal antibody blockade of CD49d on circulating leukocytes prior to allergen challenge inhibits bronchoalveolar lavage fluid eosinophilia without altering airway hyperreactivity, IL-4 or -5 production, or mucus hypersecretion [25]. Treatment of OVA-sensitised/challenged mice with soluble IL-4 receptor also blocks the influx of eosinophils into the airways without reducing airway hyperreactivity in response to methacholine challenge. Although bronchial subepithelial fibrosis has been 
correlated with airway responsiveness to methacholine [4], other studies of patients with asthma have failed to demonstrate a correlation between the degree of airway inflammation and bronchial hyperresponsiveness [55, 56].

In summary, a marked increase in the extracellular matrix protein laminin and laminin-1 receptor was demonstrated in the lungs of mice with chronic allergen-induced airway remodelling. In the present mouse asthma model, corticosteroid treatment initiated at the onset of airway inflammation was found to be effective in blocking the increase in airway laminin and laminin-1 receptor expression. The reduction in expression of laminin and its high-affinity receptor, laminin-1 receptor, in the airways by corticosteroids may help limit the remodelling process in the lungs of patients with asthma. Current treatment practices are insufficient to assess the impact of corticosteroids on airway remodelling in patients with asthma. In order to address this important therapeutic issue regarding whether the natural course of asthma and development of airway remodelling is alterable, clinical studies are needed with very early corticosteroid treatment at disease onset in patients with asthma. Such studies would also help delineate the precise relationship between airway remodelling and bronchial hyperresponsiveness.

Acknowledgements. The authors thank G.K.S. Chiang, F. Jones and Y-T. Tien for excellent technical assistance and R. Norris for typing this manuscript.

\section{References}

1. Roche WR, Beasley R, Williams JH, Holgate ST. Subepithelial fibrosis in the bronchi of asthmatics. Lancet 1989; 1: $520-524$.

2. Hoshino M, Nakamura Y, Sim JJ. Expression of growth factors and remodeling of the airway wall in bronchial asthma. Thorax 1998; 53: 21-27.

3. Jeffery PK. Remodeling in asthma and chronic obstructive lung disease. Am J Respir Crit Care Med 2001; 164: S28-S38.

4. Boulet LP, Laviolette M, Turcotte $\mathrm{H}$, et al. Bronchial subepithelial fibrosis correlates with airway responsiveness to methacholine. Chest 1997; 112: 45-52.

5. Elias JA, Zhu Z, Chupp G, Homer RJ. Airway remodeling in asthma. J Clin Invest 1999; 104: 1001-1006.

6. Timpl R, Brown JC. The laminins. Matrix Biol 1994; 14: 275281.

7. Colognato $\mathrm{H}$, Yurchenco PD. Form and function: the laminin family of heterotrimers. Dev Dyn 2000; 218: 213-234.

8. White SR, Wojcik KR, Gruenert D, Sun S, Dorscheid DR Airway epithelial cell wound repair mediated by $\alpha$-dystroglycan. Am J Respir Cell Mol Biol 2001; 24: 179-186.

9. Burgeson RE, Chiquet M, Deutzmann R, et al. A new nomenclature for the laminins. Matrix Biol 1994; 14: 209211.

10. Malinda KM, Kleinman HK. The laminins. Int $J$ Biochem Cell Biol 1996; 28: 957-959.

11. Schuger L. Laminins in lung development. Exp Lung Res 1997; 23: 119-129.

12. Warburton D, Schwarz M, Tefft D, Flores-Delgado G, Anderson KD, Cardoso WV. The molecular basis of lung morphogenesis. Mech Dev 2000; 92: 55-81.

13. Schuger L, Varani J, Killen PD, Skubitz AP, Gilbride K. Laminin expression in the mouse lung increases with development and stimulates spontaneous organotypic rearrangement of mixed lung cells. Dev Dyn 1992; 195: 43-54.

14. Lallemand AV, Ruocco SM, Gaillard DA. Synthesis and expression of laminin during human foetal lung development. Anat Rec 1995; 242: 233-241.
15. Schuger L, Skubitz AP, de las MA, Gilbride K. Two separate domains of laminin promote lung organogenesis by different mechanisms of action. Dev Biol 1995; 169: 520-532.

16. Schuger L, Skubitz AP, Gilbride K, Mandel R, He L. Laminin and heparan sulfate proteoglycan mediate epithelial cell polarization in organotypic cultures of embryonic lung cells: evidence implicating involvement of the inner globular region of laminin beta 1 chain and the heparan sulfate groups of heparan sulfate proteoglycan. Dev Biol 1996; 179: $264-273$.

17. Tourkin A, Anderson T, LeRoy EC, Hoffman S. Eosinophil adhesion and maturation is modulated by laminin. Cell Adhes Commun 1993; 1: 161-176.

18. Georas SN, McIntyre BW, Ebisawa M, et al. Expression of a functional laminin receptor $\left(\alpha_{6} \beta_{1}\right.$, very late activation antigen-6) on human eosinophils. Blood 1993; 82: 2872-2879.

19. Wicha MS, Huard TK. Macrophages express cell surface laminin. Exp Cell Res 1983; 143: 475-479.

20. Altraja A, Laitinen A, Virtanen I, et al. Expression of laminins in the airways in various types of asthmatic patients: a morphometric study. Am J Respir Cell Mol Biol 1996; 15: 482-488.

21. Lemjabbar H, Gosset P, Lamblin C, et al. Contribution of $92 \mathrm{kDa}$ gelatinase/type IV collagenase in bronchial inflammation during status asthmaticus. Am J Respir Crit Care Med 1999; 159: 1298-1307.

22. Henderson WR Jr, Tang L-O, Chu S-J, et al. A role for cysteinyl leukotrienes in airway remodeling in a mouse asthma model. Am J Respir Crit Care Med 2002; 165: 108116.

23. Hamelmann E, Schwarze J, Takeda K, et al. Noninvasive measurement of airway responsiveness in allergic mice using barometric plethysmography. Am J Respir Crit Care Med 1997; 156: 766-775.

24. Timpl R, Rohde H, Robey PG, Rennard SI, Foidart JM, Martin GR. Laminin - a glycoprotein from basement membranes. J Biol Chem 1979; 254: 9933-9937.

25. Henderson WR Jr, Chi EY, Albert RK, et al. Blockade of CD49d $\left(\alpha_{4}\right.$ integrin) on intrapulmonary but not circulating leukocytes inhibits airway inflammation and hyperresponsiveness in a mouse model of asthma. J Clin Invest 1997; 100: 3083-3092.

26. Henderson WR Jr, Lewis DB, Albert RK, et al. The importance of leukotrienes in airway inflammation in a mouse model of asthma. J Exp Med 1996; 184: 1483-1494.

27. Henderson WR Jr, Chi EY, Maliszewski CR. Soluble IL-4 receptor inhibits airway inflammation following allergen challenge in a mouse model of asthma. J Immunol 2000; 164: 1086-1095.

28. Bolender RP, Hyde DM, Dehoff RT. Lung morphometry: a new generation of tools and experiments for organ, tissue, cell, and molecular biology. Am J Physiol 1993; 265: L521L548.

29. Gundersen HJ, Jensen EB. The efficiency of systematic sampling in stereology and its prediction. J Microsc 1987; 147: 229-263.

30. Bertram JF, Bolender RP. Counting parenchymal cells in the goat lung with serial section reconstruction and stereology. Am Rev Respir Dis 1986; 133: 891-898.

31. Glover S, de Carvalho MS, Bayburt T, et al. Translocation of the $85-\mathrm{kDa}$ phospholipase $\mathrm{A}_{2}$ from cytosol to the nuclear envelope in rat basophilic leukemia cells stimulated with calcium ionophore or IgE/antigen. J Biol Chem 1995; 270: 15359-15367.

32. Lee CG, Homer RJ, Zhu Z, et al. Interleukin-13 induces tissue fibrosis by selectively stimulating and activating transforming growth factor $\beta(1)$. $J$ Exp Med 2001; 194: 809-821.

33. Kawata Y, Suzuki H, Higaki Y, et al. ben-1 elementdependent activation of the laminin gamma 1 chain gene by the cooperative action of transcription factor E3 (TFE3) and Smad proteins. J Biol Chem 2002; 277: 11375-11384.

34. Nguyen NM, Bai Y, Mochitate K, Senior RM. Laminin 
$\alpha$-chain expression and basement membrane formation by MLE-15 respiratory epithelial cells. Am J Physiol Lung Cell Mol Physiol 2002; 282: L1004-L1011.

35. Vliagoftis H, Metcalfe DD. Characterization of adhesive interactions between mast cells and laminin isoforms: evidence of a principal role for alpha 6 integrin. Immunology 1997; 92: 553-560.

36. Alnahhas MH, Karathanasis P, Kriss VM, Pauly TH, Bruce MC. Elevated laminin concentrations in lung secretions of preterm infants supported by mechanical ventilation are correlated with radiographic abnormalities. J Pediatr 1997; 131: 555-560.

37. Khan KM, Falcone DJ. Role of laminin in matrix induction of macrophage urokinase-type plasminogen activator and 92-kDa metalloproteinase expression. J Biol Chem 1997; 272: 8270-8275.

38. Faisal Khan KM, Laurie GW, McCaffrey TA, Falcone DJ. Exposure of cryptic domains in the alpha 1-chain of laminin1 by elastase stimulates macrophages urokinase and matrix metalloproteinase-9 expression. J Biol Chem 2002; 277: 13778-13786.

39. Yurchenco PD, Quan Y, Colognato H, et al. The $\alpha$ chain of laminin-1 is independently secreted and drives secretion of its $\beta$-and $\gamma$-chain partners. Proc Natl Acad Sci USA 1997; 94 : 10189-10194.

40. Blyth DI, Wharton TF, Pedrick MS, Savage TJ, Sanjar S. Airway subepithelial fibrosis in a murine model of atopic asthma: suppression by dexamethasone or anti-interleukin-5 antibody. Am J Respir Cell Mol Biol 2000; 23: 241-246.

41. Trifilieff A, El Hashim A, Bertrand C. Time course of inflammatory and remodeling events in a murine model of asthma: effect of steroid treatment. Am J Physiol Lung Cell Mol Physiol 2000; 279: L1120-L1128.

42. Vanacker NJ, Palmans E, Kips JC, Pauwels RA. Fluticasone inhibits but does not reverse allergen-induced structural airway changes. Am J Respir Crit Care Med 2001; 163: 674-679.

43. Vanacker NJ, Palmans E, Pauwels RA, Kips JC. Fluticasone inhibits the progression of allergen-induced structural airway changes. Clin Exp Allergy 2002; 32: 914-920.

44. Vanacker NJ, Palmans E, Pauwels RA, Kips JC. Effect of combining salmeterol and fluticasone on the progression of airway remodeling. Am J Respir Crit Care Med 2002; 166: 1128-1134.

45. Johnson PR, Black JL, Carlin S, Ge Q, Underwood PA. The production of extracellular matrix proteins by human passively sensitized airway smooth-muscle cells in culture: the effect of beclomethasone. Am J Respir Crit Care Med 2000; 162: 2145-2151.
46. Jeffery PK, Godfrey RW, Adelroth E, Nelson F, Rogers A, Johansson SA. Effects of treatment on airway inflammation and thickening of basement membrane reticular collagen in asthma. A quantitative light and electron microscopic study. Am Rev Respir Dis 1992; 145: 890-899.

47. Hoshino M, Nakamura Y, Sim JJ, et al. Inhaled corticosteroid reduced lamina reticularis of the basement membrane by modulation of insulin-like growth factor (IGF)-I expression in bronchial asthma. Clin Exp Allergy 1998; 28: 568577.

48. Laitinen LA, Laitinen A, Haahtela T. A comparative study of the effects of an inhaled corticosteroid, budesonide, and a $\beta_{2}$-agonist, terbutaline, on airway inflammation in newly diagnosed asthma: a randomized, double-blind, parallelgroup controlled trial. J Allergy Clin Immunol 1992; 90: 3242.

49. Laitinen A, Altraja A, Kampe M, Linden M, Virtanen I, Laitinen LA. Tenascin is increased in airway basement membrane of asthmatics and decreased by an inhaled steroid. Am J Respir Crit Care Med 1997; 156: 951-958.

50. Karjalainen EM, Laitinen A, Sue-Chu M, Altraja A, Bjermer L, Laitinen LA. Evidence of airway inflammation and remodeling in ski athletes with and without bronchial hyperresponsiveness to methacholine. Am J Respir Crit Care Med 2000; 161: 2086-2091.

51. Karjalainen EM, Laitinen A, Sue-Chu M, Larsson L, Bjermer L, Laitinen LA. Effect of inhaled budesonide on airway inflammation in young cross-country skiers. $\mathrm{Am}$ J Respir Crit Care Med 1998; 157: A98.

52. Laitinen LA, Altraja A, Karjalainen EM, Laitinen A. Early interventions in asthma with inhaled corticosteroids. J Allergy Clin Immunol 2000; 105: S582-S585.

53. Leigh R, Ellis R, Wattie J, et al. Dysfunction and remodeling of the mouse airway persist after resolution of acute allergeninduced airway inflammation. Am J Respir Cell Mol Biol 2002; 27: 526-535.

54. Ellis R, Leigh R, Southam D, O'Byrne PM, Inman MD. Morphometric analysis of mouse airways after chronic allergen challenge. Lab Invest 2003; 83: 1285-1291.

55. Ollerenshaw SL, Woolcock AJ. Characteristics of the inflammation in biopsies from large airways of subjects with asthma and subjects with chronic airflow limitation. Am Rev Respir Dis 1992; 145: 922-927.

56. Crimi E, Spanevello A, Neri M, Ind PW, Rossi GA, Brusasco V. Dissociation between airway inflammation and airway hyperresponsiveness in allergic asthma. Am J Respir Crit Care Med 1998; 157: 4-9. 